\title{
THE NEW TECH EFFECT: A COMPARATIVE ANALYSIS OF TWO UNIVERSITIES
}

\author{
Karen L. Paullet, Robert Morris University, paullet@rmu.edu \\ Gary Alan Davis, Robert Morris University, davis@rmu.edu \\ Simone K. McMillion, Middle Georgia State College, simone.mcmillion@maconstate.edu \\ Johnathan Yerby, Middle Georgia State College, johnathan.yerby@maconstate.edu
}

\begin{abstract}
In past studies, proponents of the CSI-Effect (Crime Scene Investigation Effect) proposed that jurors tend to acquit suspects when forensic evidence is not as prevalent as it is in television crime dramas. The newer "Tech-Effect" (Technology Effect) proponents argue that crime dramas do not influence jurors; rather, jurors have heightened expectations for technical and scientific evidence simply because technology is so prevalent. It is further argued that the heightened expectations for technological and digital evidence may increase a juror's tendency to acquit a suspect. This study surveyed 107 students in a mid-sized, Southeastern state college to determine if a Tech-Effect exists, and if so, could this effect have a negative impact on juror credibility? A follow-up to a 2011 study, the current research attempted to answer two questions: 1) Will students in IS/IT degree programs demonstrate greater knowledge of forensic technology in cases involving digital evidence?, and 2) Will students in IS/IT programs demonstrate higher acquittal rates in cases involving digital evidence? The findings of the current study address the two research questions above and provide further evidence of a "tech-effect" in our society. In addition, the results revealed interesting differences between the two studies.
\end{abstract}

Keywords: Tech-Effect, CSI-Effect, Computer Forensics, Network Forensics and Information Security

\section{INTRODUCTION}

The "CSI-Effect" is a term that has been coined by the media to describe the potential impact that CSI (Crime Scene Investigation) -type television shows (i.e., those that depict forensic science as a major part of the fictional investigations) have on jurors in the U.S. criminal justice system. Some authors have argued that jurors who watch television crime shows tend not to convict suspects because procedures and forensic technology observed from the shows were not applied to the case [10]. However, the actual impact (if any) of the CSI-Effect on the outcome of court trials continues to be a topic of dispute. Many researchers have attributed any noted influence on jurors to a much broader "Tech-Effect." Both the "CSI-Effect" and the more general, "Tech-Effect" are explored in the current research; the CSI-Effect is discussed first.

Many researchers have conducted studies on the CSI-Effect with mixed results. For example, A.P. Thomas surveyed 102 prosecutors and concluded that the prosecutors perceive the CSI-Effect to exist [21]. Of the prosecutors who were surveyed in the study, $38 \%$ believed that they had a trial that resulted in an acquittal or "hung" jury (i.e., a jury that is "deadlocked" and cannot reach a verdict) because forensic evidence was not available. The study recognized that it is common (after a verdict has been delivered) for attorneys to survey jurors on how the jurors came to their decision.

In 2008, G. Thomas conducted a study on the CSI-Effect that included 455 law enforcement agencies in North Carolina [22]. Out of the 264 (58\% response rate) agencies that responded to the survey, a large majority (74.6\%) agreed that CSI-type television shows are changing the way law enforcement collects evidence and conducts 


\section{Issues in Information Systems \\ Volume 14, Issue 2, pp.12-22, 2013}

investigations. The results of this 2008 study show that “ . . the law enforcement respondents overwhelmingly claim that their agency has changed their law enforcement practices to overcome a perceived CSI effect" [22].

While the above studies provide evidence for a CSI-Effect, other studies have found little to no evidence of the CSIEffect. Schweitzer and Saks, for example, surveyed 48 university students to determine if watching television crime shows had a marked impact on how a potential juror might decide in a case) [17]. In this study, the researchers presented the 48 participants with a courtroom transcript from a hypothetical criminal trial. The simulated trial involved a hair sample that was left at the crime scene by the suspect. The transcript also contained simulated "testimony" typical of a hair identification expert. After reading the transcript, participants were asked how they would decide if they were serving on a jury for the case. The results of the study revealed that there was no statistically significant difference in conviction rates between participants who reported watching television crime shows and participants who did not watch such shows. The study revealed, however, that viewers of such shows did expect more forensic science to be available in court cases: " . . people who watch such television programs regularly expect better science than what they are often presented with in courts" [17].

In 2007, Kim, Barak, and Shelton surveyed 1,027 people who had been called for jury duty. Jurors' television viewing habits was compared to expectations that forensic evidence would be introduced during the course of the trial [18]. Similar to the Schweitzer and Saks study, this study also found that jurors had increased expectations regarding forensic evidence. Unlike the Scheitzer and Saks study, however, the Kim, et al. study did not find a link between the viewing of television crime shows and heightened expectations regarding forensic evidence.

As stated by Gabel, in relation to the CSI Effect, "there is a great temptation to substitute information that is heard in the absence of knowledge that is learned" [9]. The author believes that CSI has not fabricated the discipline of forensic science, but rather that the CSI Effect started with familiar basic concepts, such as fingerprints. In order to package the familiar concepts to a television audience, exaggerated technology is used to glamorize the profession and the techniques used in the criminal justice system.

In order to conduct a more conclusive study, the authors of the current research explored the CSI-Effect in a 2010 study [6]. Like many others in this field, however, the researchers in the 2010 study found indications of a CSIEffect on the beliefs of participants, but failed to find a correlation between these beliefs and actual courtroom behavior. The lack of conclusive findings led the authors to explore what some have called the "Tech-Effect." The Tech-Effect dismisses the notion that television crime dramas alone can alter juror expectations. Rather, this newer, more general theory, surmises that any potential juror influence arises from the much broader impact of modern scientific and technological advances [20]. It has been noted by Socio-legal scholars that indeed, media alone has not and will not impact juror behavior, because much of what is discussed in CSI-type television series relies on anecdotes and retelling of "horror stories" [4]. For these Socio-legal scholars, the notion of these factors influencing juror behavior remains unfounded and these scholars concede to a more broad influence (i.e., the Tech-Effect).

Since the Tech-Effect has numerous definitions and applications in current research, the authors of the current study chose to isolate a previously unexamined aspect of the Tech-Effect, namely, the influence of technology education resulting from instruction in an Information Systems/Information Technology (IS/IT) degree program. Research participants (discussed in Methods and Procedures) included college students enrolled in IS/IT degree programs and in Non-IS/IT programs. Statistical tests were performed to identify any significant difference between the experimental group (i.e., IS/IT students) and the control group (i.e., Non-IS/IT students). 


\section{Issues in Information Systems}

Volume 14, Issue 2, pp.12-22, 2013

\section{RESEARCH QUESTIONS}

The current study attempted to gather and analyze data concerning a specific aspect of the Tech-Effect by asking the following research questions:

1. Do students in IS/IT degree programs demonstrate greater knowledge of forensic technology (than students in Non-IS/IT degree programs) in cases regarding digital evidence?

2. Do students in IS/IT programs demonstrate higher acquittal rates (than students in Non-IS/IT degree programs) in cases involving digital evidence?

\section{RELATED RESEARCH}

The Tech-Effect (i.e., Technology Effect) is a generic term with countless definitions and applications. In its broadest sense, the Tech-Effect is the impact which advances in science and technology have on various aspects of culture. In this sense, the "Tech-Effect" has been used to describe the impact of technological innovations on everything from motion pictures to men's disposable razors [3].

In terms of academic research, the Tech-Effect has typically been studied to determine its impact on education and student learning. For example, numerous studies have been conducted to determine whether or not investments in classroom technology have a positive impact on traditional K through 12 learning. In a 2000 study, researchers from Morehead University and Iowa State University studied the impact of computerized dissection on middleschool biology classes. The researchers found that students who used computerized dissection software in addition to physical dissection learned significantly more about a frog's anatomy than students who only performed the physical dissection [1]. A similar, 2001 study compared grade school students who had read CD-ROM storybooks to students who had read traditional hard-bound books. As in the previous study, the 2001 study revealed that the students who had used the technology-enabled CD-ROM books scored significantly higher on examinations regarding reading comprehension [8].

Studies analyzing the Tech-Effect on the legal system, however, are not as common. The literature regarding the Tech-Effect and the criminal justice system has focused on jurors texting and tweeting during trials. The "TwitterEffect" or "Google-Mistrials," which involve the use of hand-held computing devices during legal proceedings, has become a serious problem through all levels of the court system [16]. In a 2010 study, law professor Thaddeus Hoffmeister analyzed juror behavior with portable computing devices and discussed several possible remedies. In an attempt to minimize the use of electronic devices during trials, Hoffmeister's study proposed a draft model of jury instruction [11]. Douglas Keene, president of the American Society of Trial Consultants, identified various categories of jurors who use portable devices during trials. Like Hoffmeister, Keene also made suggestions for instructing jurors and for imposing penalties on defiant jurors [12].

Although they did not set out initially to analyze the Tech-Effect, Baskin and Sommers discussed the Tech-Effect in their follow-up study on the CSI-Effect. When they failed to find statistically-significant evidence of the CSI-Effect in their 2010 study, the authors presented the following explanation: 


\section{Issues in Information Systems \\ Volume 14, Issue 2, pp.12-22, 2013}

... the general public has had, over the past thirty years, increasing exposure to and experience with such a wide range of scientific and technological advances that they "naturally" expect the trial venue to be similarly affected and, therefore, rely on scientific evidence wherever appropriate [2].

To date, there are no comprehensive or conclusive studies on the Tech-Effect . . its existence and whether or not it affects juror credibility. Clearly, more research is warranted to determine whether or not it exists, and, more importantly, whether or not such an effect influences the decisions made by jurors in the U.S. criminal justice system.

Judge Donald E. Shelton, along with Gregg Barak and Young Kim surveyed 1027 people who had been called for jury duty in the Washington Circuit Court in 2006 [13]. The survey was administered to potential jurors prior to jury selection. Participants were asked about their television viewing habits of crime related shows and whether or not they believed the programs accurately portrayed the criminal justice system. The study showed that jurors who watch CSI, also watched other law related programs. The more frequently the juror viewed a particular crime-related program, the more accurately they perceived the program to be. Forty-six percent (46.3\%) of those surveyed expected the prosecution to present more scientific evidence. CSI watchers, as a group, have higher expectations about scientific evidence than non-CSI watchers. The study, however, did not find that watching crime related television shows had a significant impact on whether jurors were likely to acquit a defendant without scientific evidence [13]. The researchers concluded that the CSI effect is not to blame; rather, a broader phenomenon, which they called the "Tech Effect," was to blame.

In 2008, Shelton, et al. conducted a comparison study in Wayne County, Michigan which was similar to the 2006 study [19]. This revised study used the above questions with slight modifications. Questions were modified to reflect changes in television programming and to test whether or not participants believed in the existence of a techeffect. Additional questions were added to determine the jurors' levels of computer usage, cell phone usage, GPS device usage, etc. The results of the new study were merged, for a total of 2,246 jurors having completed the survey from both counties. Jurors' expectations that the prosecution would present scientific evidence exceeded the researchers' predictions for the study. Specifically, over 58\% of jurors in the study expected to see some type of scientific evidence; $42 \%$ expected to see DNA, and 56\% expected to see fingerprint evidence in every case [20]. In spite of these expectations, neither study found evidence of the existence of a CSI-Effect.

The data collected from the Wayne County study showed that $87 \%$ of jurors had a computer in their home, $92 \%$ had cell phones, and over $40 \%$ could access the Internet through their phones. The study indicated that the more sophisticated jurors were with their use of technological innovations, the more they expected the prosecution to use scientific evidence to present its case [20]. The researchers concluded from the combined study (Washtenaw County, 2006 and Wayne County, 2009) that jurors generally expect the use of scientific evidence in criminal trials. These expectations result, largely, from what the researchers called the tech-effect; a general awareness of and regular use of technological innovations, with a resulting expectation to see these and other innovations used in the criminal justice system. Shelton et al. believe that the increased juror expectations for scientific/technological evidence are grounded in a mass-mediated tech-effect, which is now ingrained in the criminal justice culture [20].

\section{METHODS AND PROCEDURES}

\section{Approach and Sample}

This study involved the administration of a survey to 107 undergraduate students enrolled in IS/IT-related degree programs and in Non-IS/IT programs. The Non-IS/IT programs included Journalism, Business, Public Service, 


\section{Issues in Information Systems \\ Volume 14, Issue 2, pp.12-22, 2013}

Respiratory Therapy, Nursing, et al. Students completed an online survey on their own time and submitted anonymous results directly into an electronic database for analysis. The students who participated in the study were attending a Southeastern State College and were 18 years of age or older. The survey was administered using Vovici Feedback, an online survey tool. The survey was active from January 15, 2013 through April 30, 2013.

The survey instrument replicated an earlier research study conducted in 2011 at a private Mid-Atlantic University [7] and was modeled after a similar research survey developed by Campbell [5]. Anecdotal accounts of the CSIEffect were represented in the survey by creating additional data collection variables. In addition, Deputy District Attorney Tom Swan from the Allegheny County District Attorney's Office, and Blase Kraeer from the City of Pittsburgh Mobile Crime Unit, assisted in creating crime scenarios based on actual cases from the criminal justice system. Survey questions were then developed from the crime scenarios.

The survey results were analyzed using SPSS (Statistical Package for the Social Sciences) statistical software. The Pearson Chi-Square and Independent Samples T-Test were used to determine whether or not a technology education received in an IS/IT degree program might affect a potential juror's decision in a criminal case. Statistical frequencies were used to determine the difference between participants enrolled in IS/IT-related programs and those not enrolled in IS/IT-related programs.

\section{Survey Instrument}

The survey instrument was designed to measure two things: 1) the participants' knowledge regarding forensic evidence, and 2) the participants' tendency to acquit a suspect (i.e., find "not-guilty"). The survey also asked participants to report their area of study in school. The area of study (i.e., degree program) was used to divide the participants into groups for comparison. The two groups consisted of students who were IS/IT majors and those who were Non-IS/IT majors.

The survey instrument consisted of a total of 40 questions. Thirty-five of the questions were closed-ended and five of the questions allowed students to type their own responses. The first question asked participants if they had ever served as a juror in a criminal court. Questions two through five addressed the participants' television viewing habits, including whether or not the participants had watched fictional television crime shows or non-fictional (i.e., documentary) television crime shows. Participants were also asked how many hours per week they watched such shows. Questions six through ten solicited demographic information from the participants, such as age-range, gender, and enrolled degree program. Questions 11 and 12 asked whether or not participants owned a mobile computing device (e.g., smartphone, laptop, or tablet PC) and if so, which mobile device. Questions 13 through 21 queried the participants' knowledge of the criminal justice system. In order to answer questions 22 through 39, participants were instructed to respond as if they had been selected to serve on a jury in a criminal court. Specifically, participants were asked to read each crime scenario and respond as if they were sitting on a jury that was assigned to the case. Participants were to use their current knowledge of U.S. law and of the U.S. criminal justice system. The final question of the survey (Question 40) asked the participants how they obtained their knowledge of the criminal justice system (i.e., from work experience, from fictional television crime shows, from non-fictional documentaries, from serving as a juror, from giving testimony, or from their formal education).

\section{RESULTS}

\section{Knowledge of Forensic Technology}




\section{Issues in Information Systems \\ Volume 14, Issue 2, pp.12-22, 2013}

In order to address the first research question (i.e., will students in IS/IT degree programs demonstrate greater knowledge of forensic technology than students in Non-IS/IT degree programs in cases regarding digital evidence?), the survey questions were designed to gauge the participants' knowledge of forensic evidence. In particular, the survey asked the following questions concerning digital evidence: 1) If a person is fingerprinted for the military, a job, or security, will that person's fingerprint be found in a criminal fingerprint database?, 2) Can a picture or video that is "pixilated" be made into a perfect photograph or perfect video image?, and 3) Is digital evidence subject to the same evidence laws as blood spatters, shell casings, and fingerprints? The results from the responses to these questions are summarized below in Tables 1 through 3.

The Pearson Chi-Square was used to determine whether or not statistically significant differences in responses existed between participants enrolled in IS/IT programs and those students not enrolled in IS/IT degree programs. As explained in the METHODS AND PROCEDURES section, Non-IS/IT programs represented included Journalism, Business, Public Service, Respiratory Therapy, Nursing, et al. Participants completed the online survey on their own time and submitted their anonymous results directly into an electronic database for analysis.

The first survey question used to gauge the students' knowledge of forensic technology concerned the national fingerprint database (i.e., If a person is fingerprinted for the military, a job, or security, will that person's fingerprint be found in a criminal fingerprint database?). A higher number $(n=26)$ of participants in IS/IT programs answered the fingerprint database question correctly, (i.e., "No" being the correct response) as compared to 22 Non-IS/IT students (see Table 1 below). However, a statistically significant difference did not exist between the two groups of students $\left(\mathrm{x}^{2}=1.476, \mathrm{p}=.224\right)$.

Table 1: Chi-Square Test Results Cross tabulation of Area of Study and "Military/Security in Fingerprint database?"

\begin{tabular}{lcccc}
\hline & \multicolumn{2}{c}{ Area of Study } & \multicolumn{2}{c}{ Chi-Square } \\
\hline In Fingerprint DB & IS/IT & Non-IS/IT & $\mathrm{X}^{2}$ & Sig. \\
\hline \multirow{4}{*}{ Yes } & 25 & 34 & 1.476 & .224 \\
\hline \multirow{4}{*}{ No } & $(-1.2)$ & $(1.2)$ & & \\
\hline Note: & 26 & 22 & & \\
\hline
\end{tabular}

The results from the second knowledge question (i.e., Can a picture or video that is "pixilated" be made into a perfect photograph or perfect video image?), are interesting (see Table 2 below). Among students enrolled in IS/IT programs, 40 answered the question correctly, compared to Non-IT/IS students, of which 35 answered the question correctly. In addition, less IS/IT students answered the question incorrectly (IS/IT $=11$, Non-IS/IT $=21$ ), which caused the difference between the student groups to approach statistical significance $\left(\mathrm{x}^{2}=3.232, \mathrm{p}=.072\right)$.

Table 2: Chi-Square Test Results Cross tabulation of Areas of Study and "Pixilated Image Made Perfect?"

\begin{tabular}{lllll}
\hline & \multicolumn{2}{c}{ Area of Study } & \multicolumn{2}{c}{ Chi-Square } \\
\hline Image Made Perfect? & IS/IT & Non IS/IT & $X^{2}$ & Sig. \\
\hline
\end{tabular}


Issues in Information Systems

Volume 14, Issue 2, pp.12-22, 2013

\begin{tabular}{lcccc}
\hline \hline & 11 & 21 & 3.232 & .072 \\
Yes & $(-1.8)$ & $(1.8)$ & & \\
\hline \multirow{2}{*}{ No } & 40 & 35 & & \\
\hline
\end{tabular}

Note: Adjusted standardized residuals appear in parentheses below group frequencies.

The final knowledge question in the survey concerned whether or not digital evidence is subject to the same evidence laws as blood spatters, shell casings, and fingerprints (i.e., Is digital evidence subject to the same evidence laws as blood spatters, shell casings, and fingerprints?). Forty-one of the participants enrolled in IS/IT programs answered this question correctly. Forty-three of the Non-IS/IT participants answered this question correctly. Based on these results, the difference between IS/IT and Non-IS/IT students was not statistically significant at the .05 threshold $\left(\mathrm{x}^{2}=0.206, \mathrm{p}=.650\right)$. For the complete results regarding this survey question, see Table 3 below.

Table 3: Chi-Square Test Results Cross tabulation of Area of Study and "Digital Evidence and the Law?"

\begin{tabular}{lcccc}
\hline & \multicolumn{2}{c}{ Area of Study } & \multicolumn{2}{c}{ Chi-Square } \\
\hline Dig. Evidence Law? & IS/IT & Non IS/IT & $X^{2}$ & Sig. \\
\hline \multirow{2}{*}{ True } & 41 & 43 & .206 & .650 \\
\hline \multirow{2}{*}{ False } & $(.5)$ & $(-.5)$ & & \\
\hline
\end{tabular}

Note: Adjusted standardized residuals appear in parentheses below group frequencies.

\section{Impact on Potential Jurors' Decisions}

In order to address the second research question (i.e., Will students in IS/IT programs demonstrate higher acquittal rates than students in Non-IS/IT degree programs in cases involving digital evidence?), the survey asked participants to read and then respond to various crime scenarios. Participants were asked to respond as if they were jurors assigned to the case in question. The survey asked participants to read and respond to the following two crime scenarios: 1) a drive-by shooting case that relied on modern, video surveillance technology, and 2) a murder case that hinged on digital evidence recovered from a computer and from the Internet.

The Independent Samples T-Test was used to determine whether statistically significant differences existed in the responses from the two groups: 1) those enrolled in IS/IT programs and 2) those not enrolled in IS/IT programs. A Likert-like scale was used to solicit participants' responses concerning the guilt or innocence of the suspects in the crime scenarios. The response scale for each crime scenario ranged from a value of 1 ("I am VERY CONFIDENT that the suspect is guilty") to a value of 6 ("I am VERY CONFIDENT that the suspect is Not Guilty").

For the drive-by shooting scenario, participants enrolled in IS/IT programs reported a higher number of "Not Guilty" judgments (i.e., acquittals) than those enrolled in Non-IS/IT programs. The mean rate of acquittals among participants who were enrolled in IS/IT programs was 3.04. Alternatively, the mean rate of acquittals among participants enrolled in Non-IS/IT programs was 2.75. Although this result supports the authors' contentions that 


\section{Issues in Information Systems \\ Volume 14, Issue 2, pp.12-22, 2013}

IS/IT students will exhibit higher acquittal rates in cases involving digital evidence, the difference is not statistically significant $(\mathrm{t}=1.419, \mathrm{p}=.159)$. For complete results, see Table 4 below.

Table 4: Independent Samples T-Test Results

Independent Samples T-Test Results of Drive by Shooting Scenario

\begin{tabular}{|c|c|c|c|c|c|}
\hline $\begin{array}{l}\text { Suspect innocent } \\
(1=\text { no confidence; } \\
6 \text { = very confident })\end{array}$ & Mean & Std. Dev. & t-test & $\mathrm{df}$ & Sig. \\
\hline Area of Study = IS/IT & 3.04 & .894 & 1.419 & 105 & .159 \\
\hline Area of Study $=$ Non IS/IT & 2.75 & 1.179 & & & \\
\hline
\end{tabular}

The final crime scenario involved a murder, which was planned using computers and the Internet. As in the previous scenario, participants were asked to weigh the evidence involved in the case scenario and decide whether they feel that the suspect is guilty or innocent. Unlike the drive-by shooting scenario, there was a recognizable difference in acquittal rates between IS/IT students $(x=3.51)$ and Non-IS/IT students $(x=2.80)$. This difference in acquittal rates between IS/IT and Non-IS/IT students was statistically significant $(t=3.508 \mathrm{p}=.001)$. The results of the T-Test from the second crime scenario do support the authors' contentions that IS/IT students will exhibit higher acquittal rates in cases involving digital evidence. See Table 5 below for complete results.

Table 5: Independent Samples T-Test Results Independent Samples T-Test Results of the AOL Murder Case

\begin{tabular}{llcccc}
\hline $\begin{array}{l}\text { Suspect innocent } \\
(1=\text { no confidence; } \\
6=\text { very confident })\end{array}$ & Mean & Std. Dev. & t-test & df & Sig. \\
\hline Area of Study $=$ IS/IT & 3.51 & 1.084 & $3.508 * *$ & 105 & .001 \\
\hline Area of Study $=$ Non IS/IT & 2.80 & .999 & & \\
\hline Note: $* *=p \leq .05$.
\end{tabular}

\section{COMPARATIVE ANALYSIS BETWEEN THE UNIVERSITIES}

As mentioned previously, the current study is a follow-up to a 2011 study in which only one University's students were surveyed $(\mathrm{n}=131)$. The 2011 study found that IS/IT students did indeed demonstrate greater knowledge of forensic technology in cases regarding digital evidence. Specifically, within the three survey questions regarding knowledge of forensic technology, the results from one question showed a statistically significant difference; and the results from one other question approached statistical significance. However, the 2011 study failed to reveal any differences in acquittal rates between IS/IT students and Non-IS/IT students [7].

Similar to the 2011 study, the current study revealed a difference in knowledge of forensic technology between IS/IT students and Non-IS/IT students. However, the degree of difference in the current study was not as pronounced as in the 2011 study. Although the IS/IT students scored higher than the Non-IS/IT students, none of the results from the three knowledge questions in the current study indicated a statistically significant difference in knowledge of forensic technology between the two groups of students. Further, the difference between the groups approached statistical significance in only one of the three knowledge questions. 


\section{Issues in Information Systems \\ Volume 14, Issue 2, pp.12-22, 2013}

In both studies (2011 and in the current study), the responses to two crime scenarios were analyzed to determine acquittal rates among the survey participants. In the 2011 study, there were no significant differences in acquittal rates between the IS/IT and Non-IS/IT students. However, in the current study, the results from both crime scenarios indicated higher acquittal rates among IS/IT students (as compared to the acquittal rates among Non-IS/IT students). More specifically, the results from one of the crime scenarios did show higher acquittal rates among IS/IT students that was statistically significant. The results from both crime scenarios in the current study support the authors' contentions that IS/IT students exhibit higher acquittal rates in cases involving digital evidence.

\section{CONCLUSIONS}

The present research surveyed undergraduate students from various college degree programs at a Southeastern State College to address the following questions: 1) Will students in IS/IT degree programs demonstrate greater knowledge of forensic technology (than students in non-IS/IT degree programs) in cases regarding digital evidence? and 2) Will students in IS/IT programs demonstrate higher acquittal rates (than students in non-IS/IT degree programs) in cases involving digital evidence?

As previously discussed, the comparison of survey results between the two Schools did reveal some interesting findings. In the original, 2011 study, the IS/IT students did seem to know more about forensics technology, however, there were no notable differences in acquittal rates between IS/IT and Non-IS/IT students. In the current study, the IS/IT students again demonstrated greater knowledge of forensic technology (albeit, less pronounced than in the 2011 study), however, the IS/IT students in the current study demonstrated higher acquittal rates.

The obvious next question would then be, "Why would the above differences exist between the two Schools?" More specifically, "Why would IS/IT students in the current study demonstrate less knowledge of digital evidence than comparable students in the 2011 study?" The researchers believe that one possible explanation for the difference could be linked to how students gain their knowledge of forensics technology and digital evidence. For example, the last question in the survey asked students "What was the main source of information that helped you provide your [survey] responses?" For their response to this question, students chose from the following: 1) from work experience in the field of forensics and/or the criminal justice system, 2) from fictional television crime shows, 3) from non-fictional documentaries on crimes, 4) from serving as a juror, 5) from testifying as a victim or witness, and 6) from a formal class on forensics. In the 2011 study, the primary source of forensic technology information reported was non-fictional documentaries on crimes. The 2011 study also showed that a high percentage of the subjects (over 12\%) worked in the field of forensics and/or criminal justice. In contrast, the primary source of forensic technology information reported in the current study was fictional television crime shows. In addition, less than $2 \%$ of the subjects in the current study worked in the field of forensics and/or criminal justice. Since fictional television crime dramas tend to be unreliable sources of forensic procedures and information, the students in the current study may be at a disadvantage in comparison to the students from the 2011 study. As previously stated, the students in the 2011 study used non-fictional documentaries and work experience as their main sources of information regarding forensic technology and digital evidence.

The differences cited above are further supported by the subjects' knowledge of the Automated Fingerprint Identification System (AFIS), which uses biometrics to compare known fingerprints to a database of fingerprint records. Students were asked "If fingerprints from the associated crime scenarios were run through a national fingerprint database system, what is the name of the system that would be used?" The correct answer to the question is the "Automated Fingerprint Identification System (AFIS)." Sixty-seven percent of students at the Mid-Atlantic University answered the question correctly in the 2011 study compared to $53 \%$ of students from the Southeastern 


\section{Issues in Information Systems \\ Volume 14, Issue 2, pp.12-22, 2013}

State College in the current study. After answering the above question, students were then asked what the acronym "AFIS" (from their prior answer) stood for. Eighteen percent of students from the Mid-Atlantic University were able to correctly define the acronym, compared to only ten percent of the students from the Southeastern State College. This finding could be attributed (as discussed previously) to the fact that $12 \%$ of the students from the MidAtlantic University work in the field of forensics and/or the criminal justice system.

As with past studies, the current study revealed that a "tech-effect" may exist in our society and does affect the knowledge of digital evidence for a potential juror. In 2007, Shelton, Barak, and Kim conducted a study to determine which factors increased jurors' knowledge of and expectations for forensic evidence [18]. The 2007 study suggested that the changes in juror knowledge and expectations were indeed the result of a "tech-effect." In a more recent example, the Casey Anthony Trial verdict in July 2011 has been questioned in light of the "tech-effect." In a recent Washington Times editorial regarding the Casey Anthony verdict, James Picht contends, "People in general have higher expectations of and confidence in technology to provide definitive answers, and when it doesn't, it affects jurors' perceptions of the strength of the prosecution's case" [15].

The findings of the current study are consistent with the Shelton, et al. study, with other studies regarding the "TechEffect," and with the opinions cited above in the Casey Anthony editorial. These studies and discussions add to the growing body of evidence that a "tech-effect" does indeed exist in our high-tech society. These studies also provide further confirmation that increased exposure to this technology does indeed raise jurors' expectations regarding the evidence available in a trial. Most notably, the current study proposes that there may be a positive relationship between increased exposure to technology and acquittal rates among jurors; and more importantly, that this relationship can be observed and measured within the limits of statistical certainty.

\section{REFERENCES}

1. Akpan, J.P. \& Andre, T.(2000). Using a computer simulation before dissection to help students learn anatomy. Journal of Computers in Mathematics and Science Teaching, (19), 297-313.

2. Baskin, D.R.. \& Sommers, I.B. (2010). Crime-show-viewing habits and public attitudes toward forensic evidence: the CSI-Effect revisited. Justice System Journal, 31(1), 97-110.

3. Bittar, C. (1999, February 22). High tech effects. Brandweek, 40(8), 3.

4. Cole, S.A. \& Dioso-Villa, R. (2009). Investigating the "CSI-Effect" Effect. Stanford Law Review, 61(6), 1350.

5. Campbell, A. (2006). The phenomenon: what is the CSI effect? Retrieved on January 5, 2010 from www.thecsi-effect.com

6. Davis, G., Paullet, K., Swan, T., \& Houck, M. (2010). Does the technology portrayed in television crime shows have an effect on potential jurors? Issues in Information Systems, 11(1), $154-163$.

7. Davis, G., Paullet, L., Grant, A.J., \& Kraeer, B. (2011). The New Tech Effect: Analyzing Juror Credibility In Cases Involving Digital Evidence. Journal of Information Systems Applied Research, 5(4), 44-54

8. Doty, D.E., Popplewell, S.R., \& Byers, G.O. (2001). Interactive CD-ROM storybooks and young readers' reading comprehension. Journal of Research on Computing in Education, 33(4), 374-383. (now Journal of Research on Technology in Education).

9. Gabel, J.D. (2010). Forensiphilia: Is the public fascination with forensic science a love affair or a fatal attraction? Georgia State University College of Law. Legal Studies Research Paper No. 2010-08

10. Heinrick, J. (2006). Everyone's an expert: the csi effect's negative impact on juries. The Triple Helix, 59-61.

11. Hoffmeister, T. (2010, August 31). Jurors in the digital age. Social Science Research Network Working Paper Series. pp. 1-44

12. Keene, D. (2010, December). Lawyers must manage and avoid Internet contamination in jury trials. The Young Lawyer, 15(3), 3 . 


\section{Issues in Information Systems}

Volume 14, Issue 2, pp.12-22, 2013

13. Kim, Y.S., Barak, G., \& Shelton, D.E. (2009). Examining the "CSI-effect" in the cases of circumstantial evidence and eyewitness testimony: multivariate and path analyses. Journal of Criminal Justice, 37 (5), 452.

14. Manning, P. (2003). Policing Contingencies. pp. 76-77

15. Picht, J. (2011, July 7). Casey Anthony and the CSI Effect. The Washington Times, Communities, p. 1A.

16. Schwartz, J. (2009, March 18). As jurors turn to Google and Twitter, mistrials are popping up. The New York Times, p. A1.

17. Schweitzer, N.J., \& Saks, M.J. (2007, Spring). The CSI effect: popular fiction about forensic science effects the public's expectations about real forensic science. Jurimetrics, 357-364.

18. Shelton, D.E., Kim, Y.S., \& Barak, G. (2007). A study of juror expectations and demands concerning scientific evidence: does the 'CSI effect' exist? Vanderbilt Journal of Entertainment \& Technology Law. 9.2 331-368.

19. Shelton, D.E. (2008). The CSI effect: does it really exist? National Institute of Justice Journal (259), 1-7.

20. Shelton, D, E. (2010). Juror expectations for scientific evidence in criminal cases: perceptions and reality about the CSI Effect myth. Thomas M. Cooley Law Review 27.1.

21. Thomas, A.P. (2006). The CSI effect on jurors and judgments. The Yale Law Journal. Pocket Part 70, 115-119.

22. Thomas, G. (2010). North Carolina law enforcement officers' perceptions regarding the CSI effect. M.A. dissertation, The University of North Carolina at Greensboro, United States, North Carolina. Retrieved March 18, 2010, from Dissertations \& Theses: A\&I. (Publication No. AAT 1456453). 